\title{
Fạbricação Digital: estratégia de inovação a profissionais e empreendimentos criativos no Estado do Ceará
}

\author{
Digital Fabrication: innovation strategies for professionals and creative enterprises in the state of Ceará
}

\author{
> Daniel Ribeiro Cardoso \\ Universidade Federal do Ceará, Brasil \\ danielcardoso@ufc.br \\ > José Aderson Araújo Passos Filho \\ Universidade Federal do Ceará, Brasil \\ aderson.passos@gmail.com
}

\author{
> Aura Celeste Santana Cunha \\ Universidade Federal do Ceará, Brasil \\ auracel@gmail.com \\ > Underléa Miotto Bruscato \\ Universidade Federal do Ceará, Brasil \\ arqlea@gmail.com
}

\begin{abstract}
This article presents the partial results of the ongoing investigations carried out for a research in the Universidade Federal do Ceará in collaboration with the Universidade Federal do Rio Grande do Sul as part of the formulation of a strategy to insert digital fabrication as a means of innovation in brazilian companies through the use of a local instance of a global network of laboratories specialized in robotized production, the Fab Labs. This first stage of the research consists in the identification of the current scenario of local productive arrangements and creative enterprises of the state of Ceará, in Brazil.
\end{abstract}

Keywords: Digital fabrication; Product design; Innovation; Creative economy.

\section{Introdução}

Os limites do projeto de produtos e serviços podem ser expandidos, ao se incorporarem fatores dinâmicos na proposta de soluçóes em um contexto contemporâneo caracterizado pelos avanços tecnológicos. Neste contexto, se torna imprescindível a condução a novas formas de pensar a prática do projeto e a prática em design por parte de profissionais e empreendedores do setores criativos e culturais no Brasil.

Neste cenário, principalmente ao que concerne a influência das tecnologias computacionais no processo contemporâneo de projeto em produçóes criativas pautadas em um modelo de açáo colaborativo, contínuo e aberto é que se insere o Fab Lab, laboratório de fabricaçáo digital do Departamento de Arquitetura e Urbanismo do Centro de Tecnologia da Universidade Federal do Ceará (DAU-UFC), constituído nos Cursos de Design Gáfico e de Produto, bem como no Cursos de Arquitetura e Urbanismo.

O presente artigo trata de um projeto que tem como parte de seu propósito definir estratégias para inserir o pensamento da Economia Criativa nas diretrizes pedagógicas nos cursos de graduação supra mencionados, tendo em vista a formação de profissionais dessas áreas que sejam capazes de enfrentar as demandas das áreas de design, arquitetura e urbanismo no contemporâneo, sobretudo aquelas relacionadas á integração das produçôes criativas ao contexto local no qual os cursos estão inseridos aos sistemas globais de economia e cultura, por diferentes aspectos.

Guiados pelo princípio da interdisciplinaridade, compartilhamento e aprendizagem através de práticas inovadoras, os Fab Labs
- redes colaborativas de conhecimento sobre fabricação digital entre instituiçóes de ensino superior - constituem-se como potencial de inovaçáo no desenvolvimento de uma idéia ou de um conceito por meio do qual um projeto de produto ou serviço pode ser delineado com o uso de modelos digitais.

Partindo do pressuposto primordial de integração entre os empreendimentos criativos, o projeto apresenta como problema de pesquisa: como as tecnologias de modelagem digital, seus processos e fundamentos, podem contribuir no Estado do Ceará para a capacidade de inovação em projetos de produtos e serviços gerados pelos agentes criativos locais? Esta pergunta está diretamente vinculada às diretrizes do Ministério da Cultura que propôe a integração de tecnologia aos empreendimentos criativos.

Diante desse problema, a pesquisa científica da qual tratase este artigo tem como objetivo principal definir estratégias de integração entre profissionais e empreendimentos no campo das criaçóes culturais e funcionais, bem como a capacitação e difusão das práticas do Fab Lab no Ceará. Desta forma, será possível constituir um terreno fértil à inovação, alinhando o projeto de pesquisa ao ensino e extensão.

\section{Metodologia}

Com base nos procedimentos técnicos utilizados, a presente pesquisa é classificada como pesquisa-ação. Uma pesquisa-ação é "um tipo de pesquisa com base empírica que é concebida e realizada em estreita associaçáo com uma ação ou com a resoluçáo de um problema coletivo e no qual os pesquisadores e participantes representativos 
da situaçáo ou problema estáo envolvidos de modo cooperativo ou participativo" (Thiollent, 1985, p. 14).

A pesquisa-ação desenvolve-se partindo de uma fase exploratória que objetiva determinar o campo de investigaçáo e a formulação do problema. Em seguida, parte-se para atividades de coleta e interpretaçáo de dados a fim de se elaborar um plano de ação para enfrentar o problema.

Essa primeira etapa de conhecimento consiste na identificação do cenário atual sobre arranjos produtivos locais (APL's) e empreendimentos criativos, e iniciou-se com um levantamento realizado junto a instituiçóes parceiras que já realizaram estudos sobre os APL's no estado do Ceará (FIEC, IEL, SEBRAE/CE e NEAPL-CE). As informações coletadas foram relativas à localização e perfil de APL's. Por meio deste levantamento, foi possível delimitar uma região e um setor de atuação para a seleção dos empreendimentos criativos passíveis de incorporarem os métodos e processos associados ao Fab Lab como estratégia de inovação.

\section{Levantamento de APL's}

Arranjos Produtivos Locais são aglomeraçóes de empresas, localizadas em um mesmo território, que apresentam especialização produtiva e mantêm vínculos de articulação, interação, cooperação e aprendizagem entre si e com outros atores locais, e dada justamente a característica colaborativa na definiçáo desse coletivo de empresas, tem-se que, através do reconhecimento do nível de atividade de cada arranjo, pode-se concluir quais seriam as empresas que mais provavelmente assimilariam os novos conhecimentos e práticas difundidos pelo Fab Lab, assegurando a repercusão das açôes promovidas pela pesquisa.

Para a identificaçáo do cenário atual sobre arranjos produtivos locais (APL's), e em reunióes com o Serviço Brasileiro de Apoio às Micro e Pequenas Empresas (SEBRAE), diretamente com responsáveis por estudos e relaçóes diretas com projetos envolvendo empresas pertinentes aos arranjos apoiados por essa instituição, constatou-se, como fonte de dados para os trabalhos realizados pelo SEBRAE, as identificaçóes e caracterizaçóes realizadas pelo Núcleo Estadual de Apoio aos APL's do Ceará (NE APL - Ceará), posto que o SEBRAE em si não é responsável por levantamentos.

Em reunião com o coordenador titular do NEAPL - Ceará, teve-se acesso ao acervo impresso da Secretaria das Cidades, que continha informaçóes sobre apresentaçóes feitas em reunióes sobre APL's casos de sucesso, anotaçóes com indicaçóes sobre os arranjos mais priorizados, quais as instituiçóes de apoio e quem liderava as ações de apoio, além de distinçóes entre APL's revelados, ainda em estruturação e os reconhecidos. Junto a isso, a Nota Técnica 05 do projeto de Análise do Mapeamento e das Políticas para Arranjos Produtivos Locais no Norte, Nordeste e Mato Grosso e dos Impactos dos Grandes Projetos Federais no Nordeste, intitulada Caracterização, Análise e Sugestôes para Adensamento das Políticas de Apoio a APL's implementadas no Estado do Ceará, descreve uma lista total de APL's levantadas em inúmeras visitas de campo, entrevistas a produtores, representantes de prefeituras, associaçóes de produtores e instituiçóes de apoio, com informaçóes atualizadas até o mês de março, do ano de 2010.
Outra instituição parceira que já realizou estudos sobre os APL's é a Federação das Indústrias do Estado do Ceará (FIEC), que conta com o Instituto Euvaldo Lodi (IEL) para o fomento de vários serviços de aperfeiçoamento, tanto para gestáo empresarial quanto para a capacitação profissional em empresas, e possui projetos em andamento com alguns APL's do estado.

Em reunião com um gestor desses projetos, três APL's foram indicados como arranjos ativos e participantes de atividades produtivas apoiadas pelo próprio IEL, sendo dois deles APL's de cerâmicas vermelhas. Além dessas informaçóes, foi obtido uma tabela contendo uma listagem de vários APL's, discriminando parceiros e açôes de apoio realizadas para cada arranjo.

\section{0 recorte de APL's}

Os dados obtidos por todas as instituiçóes visitadas foram analisados e reestruturados em uma nova tabela, mapeando todas as interseçóes entre as diferentes fontes e associando informaçóes dentro de dois grupos de descriçóes: um, onde a situação do arranjo é disposta em termos de atividades sendo realizadas (pelo APL e/ou instituição de apoio ao mesmo), o reconhecimento e a prioridade para os apoios, e a existência de um Plano de Desenvolvimento Preliminar (PDP); e um segundo grupo de informaçóes relacionadas aos parceiros dos arranjos, onde todos são listados e apenas um se mostra como líder dessas atividades de apoio. Outros campos da tabela foram previstos para o preenchimento com formas de contato e descriçẫo de cada atividade.

As atividades dos APL's selecionados foram filtradas mediante as suas respectivas compatibilidades com a fabricaçáo digital, como descrito adiante. Todos os APL's dispostos na nova tabela se fazem pertinentes a uma das seguintes especialidades: calçados, couro, cerâmica, artesanato, materiais recicláveis, confecção, redes de dormir, jóias folheadas e móveis.

\section{APL's de calçados}

O ramo de calçados é um campo fértil para a aplicação de conceitos de customizaçáo em série, onde os produtos são projetados de acordo com as necessidades individuais dos usuários, viável através de técnicas de fabricação digital.

Uma aplicação recorrente é a produçáo de palmilhas ergonômicas, adaptadas à planta do pé de cada usuário. Em um projeto para o portfólio de apresentação para os APL's, o modelo da palmilha é criado por softwares a partir de capturas simples de imagens do pé através de um scanner 2D convencional e pode ser materializado através de moldes fabricados com fresadoras CNC. Os mesmos moldes também podem ser utilizados para a fabricação de sandálias ortopédicas.

Palmilhas ortopédicas melhoram a qualidade de vida de todos que sofrem com dores nos pés, nos tornozelos, nos joelhos e nas costas devido à má postura ou a problemas nos pés e na pisada. Corrigem o alinhamento dos pés, dos tornozelos e dos joelhos reduzindo ou eliminando as dores. As palmilhas também redistribuem as pressóes na planta dos pés, reduzindo a pressão nas áreas de dor. São especialmente indicadas para idosos, diabéticos, atletas e pessoas que trabalham em pé. A inexistência desses produtos nos mercados locais configura sua produção como uma estratégia de inovação. 


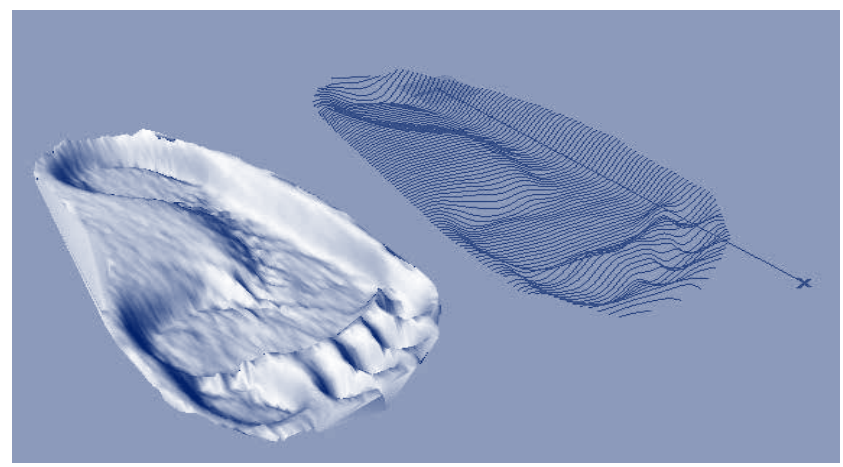

Figura 1: Palmilhas ergonômicas: projeto em andamento para a modelagem paramétrica de palmilhas a partir de imagens de um scanner comum.

Outra aplicação é a produção de calçados femininos de couro ornamentados com corte a laser, permitindo a gravação, texturizaçáo e corte dos calçados, criando com rapidez produtos com alto nível de detalhes e acabamento.

\section{APL's de couro}

O couro é um material que possui grande potencial para ser trabalhado com corte computadorizado. Através do desenho auxiliado por computador pode-se obter peças muito detalhadas com grande rapidez e precisão. O corte a laser permite a gravação, a texturizaçáo e o corte de peças, abrindo uma vasta gama de possibilidades para criação de produtos. Também é possível trabalhar com máquinas CNC de corte, que permitem cortar, gravar, furar, usinar, vincar e traçar com caneta de plotagem, além de trabalhar com peças maiores e com maior velocidade.

\section{APL's de cerâmica}

Um dos processos da produção de cerâmica envolve a utilização de moldes de gesso para fixar a argila no formato desejado. Através de modelagem em software e de fresadoras CNC é possível a criação de moldes com maior complexidade, resultando em produtos inovadores.

\section{APL's de artesanato}

O processo de fabricação digital pode ser definido, ainda que em uma escala menor, como um processo com aspectos artesanais. A "mão" é presente, mas de forma resumida. $\mathrm{O}$ artesanato, além da relação com o trabalho manual, é marcada pela subjetividade de quem o realiza, criando objetos únicos e originais. A fabricação digital pode ser uma maneira de levar tais subjetividade e originalidade a produtos repetíveis, produzidos em escala maior, mas cada um ainda guardando características de um trabalho original.

\section{APL's de materiais recicláveis}

O APL de materiais recicláveis é, a princípio, de pouco interesse para o projeto, pois o uso de materiais recicláveis dentro da fabricação digital é voltado para, reutilizando materiais próprios ao desenvolvimento de produtos através do processo (madeira, plástico PLA, etc.), o desenvolvimento de novos produtos. Os tipos de materiais reciclados e sua finalidade para a APL não dá a esta um potencial

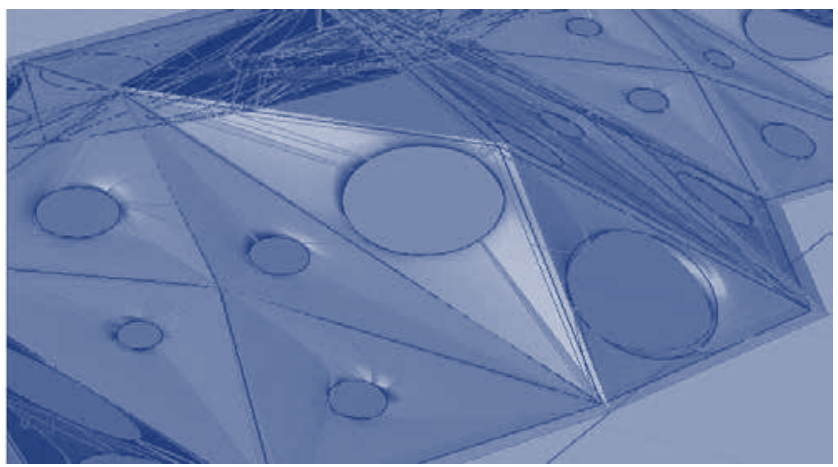

Figura 2: Cobogós paramétricos: produto desenvolvido em workshop na UFRGS, trata-se de componentes paramétricos de cerâmica modelados a partir de parâmetros de insolação.

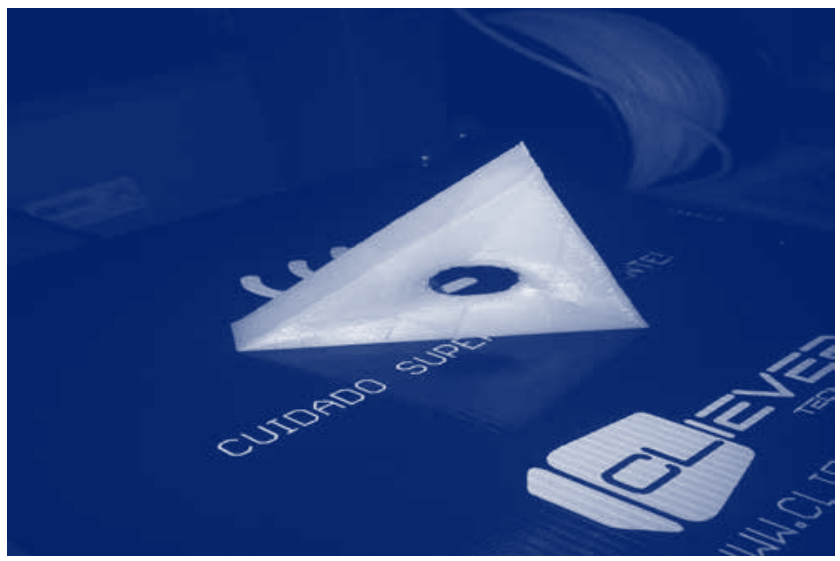

Figura 3: Cobogó materializado: impressão 3D de um dos componentes cerâmicos gerados no workshop, representado em PLA na imagem.

significante para uma possível parceria, mas em um primeiro contato, não se descarta as poucas possibilidades.

\section{APL's de confecção}

O campo de confecçáo tem um grande potencial a ser explorado pelos processos de fabricação digital. Técnicas como impressão $3 \mathrm{D}$ podem ser utilizados para o desenvolvimento de acessórios para peças de roupas ou mesmo para fabricação de uma peça de roupa completa, fazendo uso de diferentes materiais na impressão, possibilitando que ideias inovadoras possam ser agregadas ao campo de confecção.

Outra possibilidade para o uso da fabricação digital na área de confecção é o corte computadorizado, onde, através do desenho auxiliado por computador (CAD), é possível realizar cortes em tecido e outros materiais com grande precisão e rapidez.

\section{APL's de redes de dormir}

Redes de dormir são facilmente assimiláveis como objetos de corte controlado digitalmente, podendo também ter o desenho adaptado aos conformes da personalização em série, levando em conta tamanho do usuário e a distância entre os suportes, bem como questóes estéticas. 
APL's de jóias folheadas

No desenho de jóias junto à prototipagem com a fabricação digital existe o potencial de se trabalhar com novas estéticas e exploraçóes formais que tirem partido do próprio corpo do usuário, trabalhando, portanto, também com a idéia da customização em massa.

\section{APL's de móveis}

Ergonomia, estética, aspectos organizacionais e estruturais podem ser definintes projetuais extremamente inovadoras quando aliadas à fabricação digital, e de muita importância no desenho de mobiliários. O conforto de móveis como cadeiras, por exemplo, pode ser posto em teste constantemente ao longo do processo de criaçáo do móvel.

\section{Questionários}

Uma vez determinadas as atividades exercidas pelos arranjos produtivos cearenses que são compatíveis com a fabricaçâo digital, necessitou-se saber quais deles estão em condiçóes ativas de participar da pesquisa e melhor usufruir das instalaçóes do Fab Lab. Para isso, foi elaborado, com base na nova Sondagem Industrial, um questionário que busca auxiliar essa primeira etapa da pesquisa, atendo-se à perguntas que buscam, separadamente, investigar expectativas e avaliaçóes de situaçôes passadas e presentes dos arranjos produtivos, por vezes através de correlaçôes entre mais de um desses tempos, e em grupos de questóes cujos intervalos avaliados podem ser divididos em curto-atual e médio prazo. Cópias do questionário foram enviadas a instituiçôes que trabalham diretamente com os APL's pré-selecionados.

Em três grupos de perguntas, sobre o grau de atividade do arranjo produtivo, seu potencial de investimento em máquinas, oficinas e laboratórios, e sobre as condiçóes gerais do APL, a análise das respostas é feita de acordo com a leitura em conjunto de cada um desses grupos, onde perguntas específicas sobre os temas mostrados em retângulos no organograma acima são feitas.

A partir das respostas foram selecionados os APL's definitivos para a participação nas atividades da pesquisa de capacitação e prestação de outros serviços dentro da nova instância local do Fab Lab.

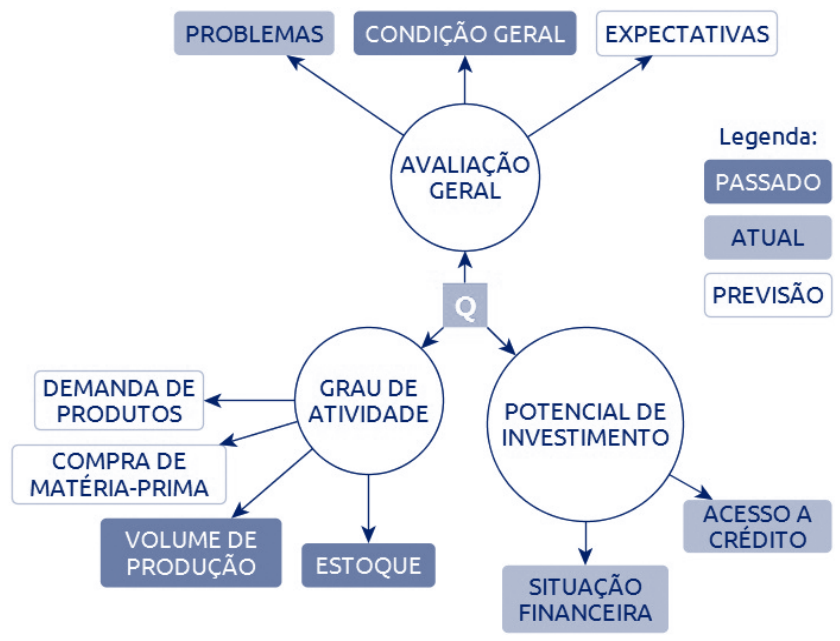

Figura 4: Organograma de perguntas: esquema geral de grupos e temas de perguntas no questionário elaborado para a sondagem dos APL's.

\section{Resultados}

Como resultado de todas as sondagens, foram encontrados vários temas compatíveis com os métodos da fabricação digital em vários APL's que já existiram e que persistem até hoje no estado do Ceará. Além disso, foi encontrado nos últimos filtros da pesquisa que os arranjos produtivos especializados no setor moveleiro, de cerâmicas vermelhas e calçados se mostraram mais ativos e provavelmente mais receptivos às inovaçôes propostas pelo Fab Lab.

Produtos já estâo sendo desenvolvidos dentro de workshops sobre modelagem paramétrica e fabricação digital para a formulação de um portfólio para a captaçáo de interesse das empresas pertinentes a esses arranjos produtivos, e planeja-se promover cursos de capacitação tanto nas máquinas $\mathrm{CNC}$, de corte a laser e impressoras $3 \mathrm{D}$ como também em novas técnicas projetuais de modelagem paramétrica, para que se assegure que todos os potenciais da fabricação digital estejam sendo passados adiante através dessas empresas.

\section{Conclusão}

O trabalho mostrou o quanto a fabricação digital é compatível com as produçóes de micro e pequenas empresas no estado do Ceará, dado o número de atividades existentes que podem ser auxiliadas e inovadas com a personalização em série e otimização paramétrica de componentes. É ainda inexistente apenas a passagem dos conhecimentos sobre essas novas técnicas, posto que, inclusive, algumas das máquinas que compoem o acervo tecnológico de um Fab Lab já são utilizadas por algumas dessas empresas, faltando, então, que haja somente uma melhor elucidação de todos os potenciais dessas tecnologias e uma maior imersão no contexto atual de projeto. É justamente para atender a falta de compartilhamento de informaçóes sobre a fabricação digital que a instância local da rede Fab Lab, através da pesquisa, irá fomentar a disseminação dos seus conhecimentos às as empresas cearenses. Com a pesquisa, entende-se também que os esforços para a melhoria do cenário empresarial micro e pequeno do estado através de um Fab Lab, implantado dentro de uma instituição de ensino superior, servirão também para estreitar os laços entre as práticas industriais, empresariais e acadêmicas, esperando-se uma relaçáo de retroalimentação de conhecimentos e recursos que, extensivamente, poderá contribuir com melhorias na educação e profissionalização de pessoas dentro e fora das universidades.

\section{Referências}

BNDES (2010), Análise do mapeamento e das políticas para arranjos produtivos locais no Norte e Nordeste do Brasil e dos impactos dos grandes projetos federais em estados nordestinos selecionados, Nota Técnica 05.

Fonseca, R. (2007) Novo Questionário da Sondagem Industrial. Documento Técnico No. 7.

Ministério da Cultura (2012). Plano da Secretaria da Economia Criativa: políticas, diretrizes e açôes, 2011 - 2014. 2ed. Brasília: Ministério da Cultura.

Neves, H. (2013). Fab Lab: A Vanguarda da Nova Revolução Industrial. São Paulo: Editorial Fab Lab Brasil.

Portal Arranjos Produtivos Locais. Disponível em <http://portalapl.ibict.br/menu/itens_menu/apls/apl_o_que_sao.html/>

Thiollent, M. (1985). Metodologia da pesquisa-ação. São Paulo: Cortez. 